\title{
Titrimetric and Spectrophotometric Determination of Some Phenothiazine Psychotropics in Pure Form and in Pharmaceutical Formulations with Metavanadate
}

\author{
Kanakapura Basavaiah* and Javarappa Manjunatha Swamy \\ Department of Chemistry, University of Mysore, Manasagangotri Mysore - 570 006, Karnataka, India
}

\begin{abstract}
Two simple, fast, accurate and precise methods for the determination of six phenothiazines and a number of their pharmaceutical formulations are described. The titrimetric method involves the oxidation of the drugs by metavanadate in sulphuric acid medium and titration of vanadium(IV) formed, with cerium(IV) using ferroin indicator and acetone as catalyst. In spectrophotometry, vanadium(IV) formed was reacted with ferriin and the resulting ferroin measured at $510 \mathrm{~nm}$. Phenothiazines in the ranges $5-100 \mathrm{mg}$ and $2.5-$ $25.0 \mu \mathrm{g} \mathrm{mL}^{-1}$ can be determined by titrimetry and spectrophotometry, respectively, with detection limits of $0.96-2.05 \mathrm{mg}$ and $0.0359-0.0565 \mu \mathrm{g} \mathrm{mL}^{-1}$, respectively. Both methods were applied successfully to the determination of the studied drugs in pharmaceutical preparations. The reliability of the assays was established by parallel determination by the official methods of British Pharmacopoeia and the results being statistically evaluated.
\end{abstract}

Key words: Phenothiazine determination; titrimetry; spectrophotometry; metavanadate; pharmaceutical formulations.

$\mathrm{N}$-substituted phenothiazines such as chlorpromazine hydrochloride $(\mathrm{CPH})$, promethazine hydrochloride $(\mathrm{PH})$, trifluperazine hydrochloride (TFPH), thioridazine hydrochloride $(\mathrm{TH})$ prochlorperazine maleate (PCPM) and prochlorperazine mesylate (PCPMS) are widely used as psychotropic and antiallergic drugs. They also possess antiemetic, sedative, antipruritic and analgesic properties [1]. They have been officially determined by titrimetry with glacial acetic acid solution of perchloric

\footnotetext{
* To whom correspondence should be addressed
}

acid or by UV-spectrophotometry [2]. Various methods have been reported for the assay of phenothiazines. Titrations with hexacyanoferrate(III) [3], chloramineT [4], N-bromosuccinimide [5], iodate [6], dichromate [7], lead picrate [8] and bismuth nitrate [9] have been proposed. But the methods using hexacyanoferrate(III), chloramine-T and dichromate involve the use of very high acid concentrations and in the NBS method the reaction stoichiometry changes with contact time. The use of lead picrate and bismuth nitrate involves the filtration of the precipitate formed before titrating the unreacted metal with EDTA.

Spectrophotometric methods based on diazotization and coupling with arylamine [10], charge-transfer complex formation [11], ion-association complex formation [12], ternary complex formation [13] or through formation of the Schiff base with p-dimethylaminobenzaldehyde [14] have also been reported. A common method of general applicability involves the formation of purple-red or orange-red radical cations when phenothiazines are oxidized by oxidants like $\mathrm{N}$ bromosuccinimide [15], chloramine-T [16], sodium cobalt(III)nitrite [17], hexacyanoferrate(III) [18], potassium periodate [19] or cerium(IV) sulphate [20] and subsequent measurement of the colour. In this method, the amounts of acid and oxidant used are critical. One of the present authors has earlier reported the titrimetric [21] and spectrophotometric [22] determination of some phenothiazines employing metavanadate as the reagent, but the titrimetric procedure employs a very high acid concentration $\left(5 \mathrm{ml}\right.$ each of $10 \mathrm{M}-\mathrm{H}_{2} \mathrm{SO}_{4}$ and $10 \mathrm{M}-\mathrm{H}_{3} \mathrm{PO}_{4}$ in a total volume of $15 \mathrm{ml}$ ) whereas in the spectrophotometric procedure the working conditions 
are critical and the coloured species is stable for only $15 \mathrm{~min}$. An indirect spectrophotometric method [23] employing metavanadate proposed earlier, requires heating and lacks sensitivity (range $50-1000 \mu \mathrm{g} \mathrm{mL}^{-1}$ ). The present work aims to demonstrate the utility of metavanadate for the indirect determination of some phenothiazines by titrimetric and spectrophotometric methods which overcome some of the drawbacks in the methods reported earlier.

\section{Experimental}

\section{Appartus}

Absorbance measurements were made using a 106 Systronics digital spectrophotometer with quartz cells of $10 \mathrm{~mm}$ pathlength.

\section{Materials and Reagents}

Analytical reagent grade chemicals and doubly distilled water were used throughout. Cerium(IV) sulphate (approx. 0.05 M) was prepared by dissolving $20 \mathrm{~g}$ of sample in $1 \mathrm{M}-\mathrm{H}_{2} \mathrm{SO}_{4}$ and diluting to one litre with the same acid. It was standardised by the iron(II) ammonium sulphate method [24]. Sodium metavanadate (approx. $0.05 \mathrm{M}$ ) was prepared by dissolving $6 \mathrm{~g}$ reagent in water and diluted to one litre. Ferriin reagent was prepared by mixing $0.198 \mathrm{~g}$ of $1,10-$ phenanthroline monohydrate, $2 \mathrm{ml}$ of $1 \mathrm{M}$ hydrochloric acid and $0.16 \mathrm{~g}$ of iron(III) ammonium sulphate and diluting to $100 \mathrm{ml}$ with water. Ferroin indicator was prepared by dissolving $1.485 \mathrm{~g}$ of the base in $100 \mathrm{ml}$ of water containing $0.695 \mathrm{~g}$ of ferrous sulphate heptahydrate. Sulphuric acid (10 M), acetic acid (10 M), ammonia (1:1) were prepared using analytical-grade reagent chemicals.

\section{Standard Solutions of Phenothiazines}

Pure drug samples were kindly provided by several pharmaceutical companies and used as received. Dosage forms containing the compounds were purchased from commercial sources. Stock standard solutions containing $5 \mathrm{mg} \mathrm{mL}^{-1}$ drug were prepared by dissolving weighed amounts of CPH (British Pharm), PH (Rhone Poulenc), TFPH (SmithKline Beecham), TH (Sandoz) PCPM and PCPMS (Rhone-Poulenc) in water. In respect of PCPM, a few drops of dil. hydrochloric acid were used for better dissolution. The solutions were kept in amber coloured bottles and stored in a refrigerator.
For spectrophotometric work, the stock solutions were diluted to $100 \mu \mathrm{g} \mathrm{mL}^{-1}$ of drug in water.

\section{Analytical Procedures}

Titrimetry. A 10 or $15 \mathrm{~mL}$ aliquot of drug solution containing 10$75 \mathrm{mg}$ CPH, 5-75 mg PH, 5-50 mg TH, 10-100 mg TFPH, PCPM or PCPMS was transferred into a $100 \mathrm{~mL}$ conical flask and $3 \mathrm{~mL}$ of $10 \mathrm{M}$ sulphuric acid were added followed by $10 \mathrm{~mL}$ of $0.05 \mathrm{M}$ vanadate solution. The reaction mixture was shaken occassionally and after a specified time (Table 1), the vanadium(IV) formed was titrated with standardised cerium(IV) sulphate solution $(0.05 \mathrm{M})$ using two drops of ferroin as indicator, and $10 \mathrm{~mL}$ acetone. From the volume of cerium(IV) sulphate consumed, the amount of the drug was calculated.

Spectrophotometry. Different aliquots, i.e., $0-2.0 \mathrm{~mL}$ of $\mathrm{CPH}$, $0-1.75 \mathrm{~mL}$ of PH, $0-2.5 \mathrm{~mL}$ of TH, $0-2.25 \mathrm{~mL}$ of TFPH, $0-3.0 \mathrm{~mL}$ of PCPM or $0-2.5 \mathrm{~mL}$ of PCPMS (each $100 \mu \mathrm{g} \mathrm{mL}^{-1}$ ) were transferred into $10 \mathrm{~mL}$ standard flasks. $0.5 \mathrm{~mL}$ of $10 \mathrm{M}-\mathrm{H}_{2} \mathrm{SO}_{4}$ were added to each flask followed by $0.5 \mathrm{~mL}$ of $0.05 \mathrm{M}$-vanadate solution. The total volume was adjusted to $4 \mathrm{~mL}$ by adding water. The contents were mixed well and let stand for specified time (Table 2) for the oxidation of the drugs to complete as indicated by the disappearance of the purple-red, red, orange-red or blue colour of the radical cation. Then, $2 \mathrm{~mL}$ of $10 \mathrm{M}$-acetic acid and $2 \mathrm{~mL}$ of ferriin reagent were added and after $5 \mathrm{~min}, 2 \mathrm{~mL}$ of $1: 1$ ammonia were added and diluted to $10 \mathrm{~mL}$ with water, mixed well and the absorbance of the coloured solution measured at $510 \mathrm{~nm}$ against the reagent blank after $10 \mathrm{~min}$. The amount of drugs was deduced from the standard calibration plots or regression equations.

\section{Procedure for Pharmaceutical Preparations}

Tablets. Twenty to one hundred tablets depending on content per tablet were weighed and ground. An amount of the powder equivalent to $500 \mathrm{mg}$ of the active component was weighed into a $100 \mathrm{~mL}$ volumetric flask, about $50 \mathrm{~mL}$ of water were added and shaken thoroughly for about $15 \mathrm{~min}$. The volume was made up to the mark with water, mixed well and filtered using a quantitative filter paper. A suitable aliquot was analysed by titrimetry. The filtrate was diluted stepwise to get $100 \mu \mathrm{g} \mathrm{mL}^{-1}$ solution of each drug and used for analysis by spectrophotometry. In respect of PCPM tablets a few drops of $1.0 \mathrm{M}-\mathrm{HCl}$ were used to aid extraction of the active component.

Injections. The contents of twenty ampoules were mixed and an accurately measured volume equivalent to $500 \mathrm{mg}$ of drug was

Table 1. Analytical data for the titrimetric determination of phenothiazines

\begin{tabular}{llclll}
\hline Drug & $\begin{array}{l}\text { Reaction time, } \\
\text { min }\end{array}$ & $\begin{array}{l}\text { Range, } \\
\mathrm{mg}\end{array}$ & $\begin{array}{l}\text { LOD, } \\
\mathrm{mg}\end{array}$ & $\begin{array}{l}\text { LOQ, } \\
\mathrm{mg}\end{array}$ & $\begin{array}{l}\text { Correlation, } \\
\text { coefficient, } \\
\mathrm{r}\end{array}$ \\
\hline CPH & 10 & $10-75$ & 1.01 & 3.38 & 0.9711 \\
PH & 10 & $5-75$ & 0.96 & 3.21 & 0.9975 \\
TH & 5 & $5-50$ & 1.23 & 4.11 & 0.9999 \\
TFPH & 20 & $10-100$ & 1.44 & 4.82 & 0.9999 \\
PCPM & 20 & $10-100$ & 1.90 & 6.04 & 0.9991 \\
PCPMS & 15 & $10-100$ & 2.05 & 6.84 & 0.9999 \\
\hline
\end{tabular}

$L O D$ Limit of detection; $L O Q$ Limit of quantification. 
Table 2. Optical characteristics for the spectrophotometric determination of phenothiazines

\begin{tabular}{|c|c|c|c|c|c|c|}
\hline Characteristics & $\mathrm{CPH}$ & $\mathrm{PH}$ & $\mathrm{TH}$ & TFPH & PCPM & PCPMS \\
\hline Reaction time (min) & 15 & 5 & 5 & 20 & 10 & 15 \\
\hline $\begin{array}{l}\text { Beer's law limits } \\
\left(\mu \mathrm{g} \mathrm{mL}^{-1}\right)\end{array}$ & $2.5-20$ & $2.5-17.5$ & $2.5-25$ & $2.5-22.5$ & $2.5-30$ & $2.5-25$ \\
\hline $\begin{array}{l}\text { Detection limit } \\
\left(\mu \mathrm{gLL}^{-1}\right)\end{array}$ & 0.0565 & 0.0501 & 0.0359 & 0.0396 & 0.0514 & 0.0527 \\
\hline $\begin{array}{l}\text { Molar absorptivitiy } \\
\left(1 \cdot \mathrm{mol}^{-1} \mathrm{~cm}^{-1}\right)\end{array}$ & $1.00 \times 10^{4}$ & $1.02 \times 10^{4}$ & $1.87 \times 10^{4}$ & $2.02 \times 10^{4}$ & $2.00 \times 10^{4}$ & $2.09 \times 10^{4}$ \\
\hline $\begin{array}{l}\text { Sandell sensitivity } \\
\left(\mathrm{ng} \mathrm{cm}^{-1}\right)\end{array}$ & 3.52 & 3.14 & 2.18 & 2.39 & 3.04 & 3.27 \\
\hline \multicolumn{7}{|l|}{$\begin{array}{l}\text { Regression } \\
\text { equation* }{ }^{*}\end{array}$} \\
\hline Intercept (a) & -0.0026 & -0.0076 & 0.0064 & 0.0085 & 0.0088 & -0.0046 \\
\hline Slope (b) & 0.0288 & 0.0325 & 0.0453 & 0.0409 & 0.0316 & 0.0308 \\
\hline $\begin{array}{l}\text { Correlation } \\
\text { coefficient (r) }\end{array}$ & 0.9990 & 0.9997 & 0.9998 & 0.9998 & 0.9994 & 0.9998 \\
\hline
\end{tabular}

${ }^{*} \mathrm{y}=\mathrm{a}+\mathrm{bx}$ where ' $\mathrm{y}$ ' is the absorbance for concentration ' $\mathrm{x}$ ' in $\mu \mathrm{g} \mathrm{mL} \mathrm{mL}^{-1}$.

transferred into a $100 \mathrm{~mL}$ volumetric flask and diluted to the mark with water. The solution was then treated as described under tablets.

\section{Results and Discussion}

Titrimetry. Of the few titrimetric procedures [25-28] available for determination of vanadium(IV), the most convenient and simple method is the titration of vanadium(IV) in acidic solution with cerium(IV) sulphate using ferroin as the indicator and acetone as the catalyst [28]. The proposed titrimetric procedure for the determination of phenothiazines is based on the oxidation of the drugs first to coloured phenothiazinium-free radicals and finally to the colourless sulphoxides $[29,30]$ by vanadate in acid medium and the titration of the resulting vanadium(IV) with cerium(IV) sulphate as described by Sriramam et al. [28]. For the oxidation of the drugs as well as the titration of vanadium(IV) an overall $\mathrm{H}_{2} \mathrm{SO}_{4}$ concentration of 2-2.5 $\mathrm{M}$ was found adequate.

All the six drugs investigated were found to react with vanadate in the ratio $1: 2$ which is in agreement with that reported earlier [21]. The relationship

Table 3. Evaluation of accuracy and precision of the proposed methods

\begin{tabular}{|c|c|c|c|c|c|c|}
\hline \multirow[t]{2}{*}{ Drug } & \multicolumn{3}{|c|}{ Titrimetric method } & \multicolumn{3}{|c|}{ Spectrophotometric method } \\
\hline & $\begin{array}{l}\text { Amount } \\
\text { taken, } \\
\text { mg }\end{array}$ & $\begin{array}{l}\text { Amount } \\
\text { found, } \\
\mathrm{mg}\end{array}$ & $\mathrm{RSD}^{*}, \%$ & $\begin{array}{l}\text { Amount } \\
\text { taken, } \mu \mathrm{g}\end{array}$ & $\begin{array}{l}\text { Amount } \\
\text { found, } \mu \mathrm{g}\end{array}$ & $\mathrm{RSD}^{*}, \%$ \\
\hline \multirow[t]{3}{*}{$\mathrm{CPH}$} & 10 & 9.85 & 0.44 & 30 & 30.21 & 0.26 \\
\hline & 30 & 29.67 & 0.76 & 100 & 102.67 & 0.33 \\
\hline & 60 & 61.44 & 0.82 & 200 & 198.06 & 0.21 \\
\hline \multirow[t]{3}{*}{ PH } & 5 & 4.94 & 1.26 & 30 & 30.42 & 0.44 \\
\hline & 30 & 30.45 & 0.65 & 90 & 91.69 & 0.72 \\
\hline & 60 & 60.66 & 1.04 & 160 & 158.22 & 0.64 \\
\hline \multirow[t]{3}{*}{$\mathrm{TH}$} & 5 & 4.89 & 0.96 & 50 & 48.67 & 1.18 \\
\hline & 20 & 19.80 & 0.34 & 150 & 148.05 & 0.39 \\
\hline & 40 & 40.80 & 0.92 & 200 & 198.34 & 0.86 \\
\hline \multirow[t]{3}{*}{ TFPH } & 10 & 10.15 & 0.63 & 40 & 40.96 & 0.52 \\
\hline & 50 & 49.86 & 0.76 & 150 & 149.37 & 0.22 \\
\hline & 80 & 81.88 & 0.26 & 200 & 201.30 & 0.36 \\
\hline \multirow[t]{3}{*}{ PCPM } & 10 & 10.14 & 1.13 & 60 & 60.22 & 0.62 \\
\hline & 50 & 50.75 & 0.54 & 200 & 203.42 & 0.18 \\
\hline & 80 & 80.74 & 0.37 & 280 & 285.06 & 0.49 \\
\hline \multirow[t]{3}{*}{ PCPMS } & 10 & 9.95 & 0.84 & 50 & 49.60 & 0.37 \\
\hline & 50 & 50.17 & 0.62 & 150 & 149.08 & 0.60 \\
\hline & 80 & 79.06 & 0.38 & 200 & 196.50 & 0.78 \\
\hline
\end{tabular}

\footnotetext{
* Average of seven determinations. RSD Relative standard deviation.
} 


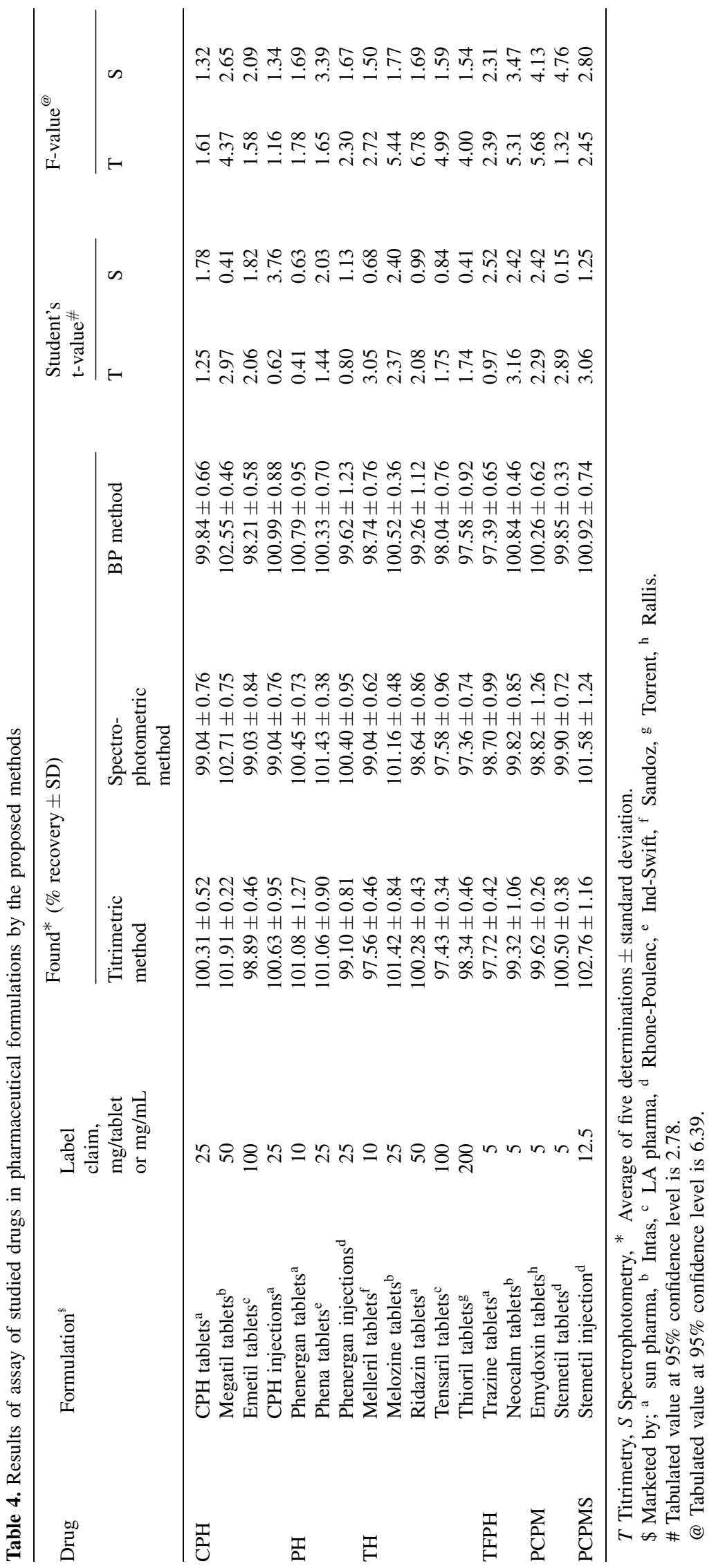


between the titration end-point and the drug amount was also examined. The linearity between the amount of the drug and titration end-point is apparent from the correlation coefficient, $\mathrm{r}$ (0.9711-0.9999), obtained by the best fit line via linear least squares treatment. The calculated values of $r$ show that the reaction between the drugs and the vanadate proceeds stoichiometrically in the ratio $1: 2$.

Spectrophotometry. One of the sensitive spectrophotometric methods reported for vanadium(IV) involves the reduction of ferriin by vanadium(IV) to orange-red ferroin and its measurement at $510 \mathrm{~nm}$ [31]. In this work, excessive vanadium(V) was used to oxidise phenothiazines in sulphuric acid medium to colourless sulphoxides and the vanadium(IV) formed was determined by reacting it with ferriin in $\mathrm{H}_{2} \mathrm{SO}_{4}-\mathrm{CH}_{3} \mathrm{COOH}$ medium and later raising the $\mathrm{pH}$ favourable for the formation of ferroin. Phenothiazines, when added in increasing amounts, consume vanadium $(\mathrm{V})$; consequently there is a concomitant rise in vanadium(IV) concentration. This is observed as a proportional increase in the absorbance of the reaction product on increasing the concentration of phenothiazines.

The various parameters involved in this study were optimised. Since the reaction: $\mathrm{Fe}(\mathrm{Phen})_{3}^{3+}+\mathrm{V}(\mathrm{IV}) \rightleftharpoons$ $\mathrm{Fe}(\mathrm{Phen})_{3}^{2+}+\mathrm{V}(\mathrm{V})$ is favourable in presence of $0.67 \mathrm{M}-\mathrm{H}_{2} \mathrm{SO}_{4}$ and $2.5 \mathrm{M}-\mathrm{CH}_{3} \mathrm{COOH}, 0.5 \mathrm{~mL}$ of $10 \mathrm{M}-$ $\mathrm{H}_{2} \mathrm{SO}_{4}$ and $2 \mathrm{~mL}$ of $10 \mathrm{M} \mathrm{CH} \mathrm{CHOH}_{3} \mathrm{CON} 2 \mathrm{~mL}$ of ferriin reagent were used to force the reaction to go to completion. A $0.5 \mathrm{~mL}$ volume of $10 \mathrm{M}-\mathrm{H}_{2} \mathrm{SO}_{4}$ in a total volume of $4 \mathrm{~mL}$ was found adequate for the oxidation of the drugs to their respective sulphoxides in a reasonable time of $5-20 \mathrm{~min}$ depending on the individual phenothiazine derivative. Since ferroin is formed in the $\mathrm{pH}$ range of 2-9, the $\mathrm{pH}$ of acidic medium employed for the redox reaction between vanadium(IV) and ferriin was raised by adding $2 \mathrm{~mL}$ of 1:1 ammonia solution which was found to be optimum. The full colour was developed in $10 \mathrm{~min}$ and was stable for several months.

Analytical Data. The reaction times, detection limits, molar absorptivities and Sandell sensitivities are given in Table 2. The slope and intercept values obtained by using linear least squares treatment of the results of the systems are also presented in Table 2. The correlation coefficients of the calibration plots are in the range 0.9990-0.9998 confirming a linear increase in absorbance with increasing concentration of drugs.
To examine the validity and the applicability of the proposed methods and the reproducibility of the results, seven replicate determinations at different concentrations of drugs were performed. The relative standard deviations were less than $2 \%$ (Table 3 ) which indicate the high precision of the methods.

The methods were applied to the assay of the studied drugs in tablets and injections. The results obtained were found to be in good agreement with those of the official methods. The calculated t- and F-values did not exceed the theoretical values indicating no significant difference between the proposed methods and official methods [1].

In pharmaceutical analysis, it is important to test the selectivity towards the excipients and fillers added to the pharmaceutical formulations. Fortunately, such materials mostly do not interfere. This is clear from the results obtained for the pharmaceutical preparations (Table 4) that the excipients do not interfere.

The proposed procedures for the determination of phenothiazines in pure form and in pharmaceutical formulations are simple and exhibit a fair degree of accuracy and precision. They are applicable over a wide dynamic concentration range, contrary to most of the reported direct methods. The spectrophotometric method is one of the highly sensitive methods ever reported for phenothiazines. The method is free from the usual analytical complications like heating, extraction, critical acid or reagent concentration and instability of the coloured species. These advantages make both methods suitable for the routine analysis of the pure drugs and their pharmaceutical formulations.

\section{References}

[1] M. Gordon (Ed.) Psychopharmacological Agents, Vol. II Academic Press, New York, 1964.

[2] The British Pharmacopoeia, Her Majesty's Stationery Office, London, 1995.

[3] A. S. Issa, M. S. Mahrous, Talanta 1984, 31, 287.

[4] A. N. Nayak, Rangaswamy, H. S. Yathirajan, P. G. Ramappa, Indian Drugs 1982, 19, 202.

[5] M. I. Walash, R. Mohamed, A. M. Abou-Ouf, F. Belal, Analyst (London) 1983, 108, 626.

[6] K. Basavaiah, J. Manjunatha Swamy, Oxidation Commun. 2000, 23, 212.

[7] K. Basavaiah, G. Krishnamurthy, Anal. Sci. 1999, 15, 67.

[8] M. Gajewska, Chem. Anal. (Warsaw) 1973, 18, 651.

[9] M. Basinska, H. Puzanowska-Tarasiewicz, M. Tarasiewicz, Acta Pol. Pharm. 1970, 27, 123.

[10] S. R. El-Shabouri, Talanta 1985, 32, 995.

[11] M. Abdel-Salam, A. S. Issa, M. S. Mahrous, M. S. AbdelHameed, Anal. Lett. 1985, 18, 1391. 
[12] K. Basavaiah, J. Manjunatha Swamy, G. Krishnamurthy, Chem. Anal. (Warsaw) 1999, 44, 1049.

[13] Y. Fujitha, I. Mori, K. Fujta, Y. Nakahashi, J. Janaka, Chem. Pharm. Bull. 1987, 35, 5004.

[14] T. P. Gandhi, M. R. Patel, A. A. Patel, V. C. Patel, Indian Drugs 1979, 16, 242.

[15] A. M. Taha, N. A. El-Rabbat, M. E. El-Kommos, I. H. Refat, Analyst (London) 1983, 108, 1500.

[16] H. Puzanowska-Tarasiewicz, A. Kojlo, Farm. Pol. 1983, 39, 141.

[17] M. S. Mahrous, M. Abdel-Khalek, Talanta 1984, 31, 285.

[18] K. Basavaiah, G. Krishnamurthy, Ann. Chim. (Rome) 1999, $89(7-8), 623$

[19] K. Basavaiah, Srilatha, J. Manjunatha Swamy, Anal. Lett. 2000, 33, 43.

[20] W. Stisinik, M. Tarasiewicz, Pharmazie 1996, 51, 62.

[21] K. Basavaiah, G. Krishnamurthy, Mikrochim. Acta 1999, 130, 197.

[22] K. Basavaiah, P. G. Ramappa, Eastern Pharm. 1984, 27, 131.
[23] S. Singh, I. C. Shukla, S. Shukla, Indian J. Pharm Sci. 1988, 50, 278.

[24] I. M. Kolthoff, R. Belcher, V. A. Stenger, G. Matsuyama, Volumetric Analysis, 1957, Vol. III. Interscience Publishers, New York.

[25] N. Venkateswara Rao, V. V. S. Eswara Dutt, Anal. Chim. Acta 1970, 51, 553.

[26] M. Zaky, W. G. Hanna, Microchem. J. 1986, 34, 235.

[27] S. A. Chimatadav, S. T. Nandibewoor, T. R. Raju, J. Indian Chem. Soc. 1989, 66, 919.

[28] K. Sriramam, B. S. R. Sarma, B. S. Sundar, N. R. Sastry, Talanta 1981, 28, 287.

[29] G. Dusinsky, O. Liskova, Chem. Zvestii 1958, 12, 213.

[30] W. G. Belikov, G. F. Moiseeva, Farmatsiya (Moscow) 1986, $36,87$.

[31] G. N. Rao, Ravi Prakash, Curr. Sci. 1974, 43, 279.

Received September 26, 2000. Revision March 25, 2001. 